\title{
Feasibility Analysis of Basic Writing and Reading Materials for Foreign Speakers
}

\author{
Muhammad Rohmadi ${ }^{1}$, Chafit Ulya ${ }^{2}$, Memet Sudaryanto ${ }^{3}$, Manuel Ximenes \\ ${ }^{123}$ Sebelas Maret University, Indonesia \\ ${ }^{4}$ Universidade Nacional Timor Lorosa'e (UNTL) \\ 1mamad r76@staff.uns.ac.id 20hafit@staff.uns.ac.id \\ 3memetsudaryanto@staff.uns.ac.id
}

\begin{abstract}
BIPA learners are foreign language speakers who are learning Bahasa Indonesia coming from various language backgrounds. Bahasa Indonesia is a foreign language in BIPA teaching. A foreign language is learnt based on a specific purpose. This is a qualitative research using content analysis approach to study the feasibility of Indonesian textbooks of basic reading material for foreign speakers. The study involved a set sample of teaching materials developed by BIPA instructors to improve the learning electability of Indonesian language learners. Good teaching materials contain various type of materials; ranging from simple basic materials to complex materials that are expected to develop world views and perceptions of the social background of native speaker communities in second learning and foreign languages. The materials developed by BIPA instructors were already inviting or influencing the reader, namely BIPA learners, to easily understand the contents of the materials and do something according to the wishes of the author. Some of the weaknesses of BIPA teaching materials, one of which was the existence of an effective sentence that must be accepted in understanding the text. A good learning material that contains elements of sentence formation must have a logical relationship so that it is easily understood by the readers. Conjunctions in sentences can be used as a means of connecting sentence elements with other elements or parts of sentences with other parts of sentences so it is not located at the beginning of a sentence. One of the effective sentence dysfunction is if the conjunction is placed at the beginning of the sentence, it will be ineffective. The dot before the conjunction in the data should be removed.
\end{abstract}

Keywords: Foreign, Language, Reading, Learning, Textbook

\section{PENDAHULUAN}

Bahasa Indonesia telah digunakan untuk komunikasi oleh orang asing yang tersebar hampir di seluruh negara sebagai bahasa asing (as foreign language) yang sebagian besar digunakan luar negeri. Orang asing yang ingin belajar bahasa Indonesia dikenal sebagai pembelajar BIPA. Bahasa Indonesia dalam pembelajaran BIPA memiliki peran bahasa asing. Bahasa asing dipelari seseorang dengan tujuan tertentu [1]. Mempelajari bahasa asing tidak seperti mempelajari bahasa ibu, bahasa ibu dipelajari secara tidak sadar dan bahasa asing dipelajari dalam keadaan sadar yang mengakibatkans eseorang perlu mempelajarinya dengan 
berbagai cara. Selin itu, banyak hal yang mempengaruhi seseorang agar mampu menggunakan bahasa asing tersebut.

Terdapat empat dimensi bahasa yang disebut sebagai keterampilan yang harus dimiliki, yaitu (1) menyimak, (2) berbicara, (3) membaca, dan (4) menulis. Hal yang menarik peneliti melakukan penelitian dalam pembelajaran BIPA adalah cara berbicara pemelajar BIPA ketika belajar bahasa Indonesia. Pemelajar BIPA memiliki ciri khas tersendiri dalam bertutur terutama dalam mengucapkan kata-kata di dalam bahasa Indonesia. Pemelajar BIPA memiliki ciri khas dalam berbicara menggunakan bahasa Indonesia, yaitu pada aspek bunyi bahasa pemelajar tersebut.

Bahasa kedua adalah bahasa resmi yang digunakan dalam sebuah negara, bahasa kedaerahan, atau bahasa asing (bukan bahasa penduduk asli). Bahasa Indonesia di Indonesia berkedudukan sebagai bahasa kedua karena di Indonesia banyak terdapat bahasa daerah yang terdapat di berbagai wilayah nusantara [2]. Selain itu, bahasa Indonesia juga dapat berkedudukan sebagai bahasa asing bagi orang asing.

Pembelajaran bahasa kedua lebih mempelajari deskripsi tentang bahasa tersebut. Namum, proses berbicara dan mendengarkan juga dilibatkan dengan elemen linguistik, elemen psikologis serta elemen lainnya. Belajar bahasa kedua tidak hanya mendeskripsikan bahasa. Belajar bahasa kedua melibatkan proses berbicara, menyimak, dan menggabungkan proses linguistik serta psikologis menjadi satu keutuhan keterampilan berbahasa.

Seorang yang memperoleh bahasa atau dwibahasawan mula-mula mendapat bahasa pertama, setelah itu baru memperoleh bahasa kedua yaitu bahasa resmi suatu negara. Pendapat Tarigan menjelaskan bahwa bahasa kedua diperoleh setelah bahsa pertama, setiap orang yang belajar bahasa kedua memiliki bahsa pertama yang dipelajari sebelumnya [3]. Bahasa kedua dapat bersifat alamiah dan faktor buatan yang dipelajari atau digunakan secara sengaja. Di Indonesia masyarakat memiliki bahasa pertama yang beragam atau berbeda-beda, tetapi memiliki bahasa kedua yang sama, yaitu bahasa Indonesia yang digunakan sebgai bahasa nasional. Bahasa Indonesia digunakan secara alamiah dan buatan tergantung proses seseorang memperoleh bahasa Indonesia.

Seseorang diharapkan dapat mengembangkan pandangan dan persepsi dunia terhadap latar belakang sosial komunitas penutur asli pada pembelajaran kedua dan bahasa asing [4]. Pemelajaran bahasa kedua tidak hanya mengacu pada unsur lingustik, tetapi seorang pemelajar juga perlu memahami dan menumbuh kembangkan pengetahuan bahasa dan tanggapan dari pengetahuan sosial penutur asli.

Pembelajaran keterampilan berbicara dan mendengar di dalam kelas selalu dikaitkan dengan ketidaksamaan, antara pendekatan yang akan dijadikan bahasa baru dan digunakan setiap berkomunikasi dalam kehidupan sehari-hari [5]. Bahasa yang dipakai mahasiswa saat pembelajaran di kelas adalah bahasa kedua yang bukan bahasa asli pemelajar BIPA, mahasiswa perlu menyesuaikan agar dapat berbicara didepan kelas. Kemampuan bahasa non penutur asli membutuhkan tahapan untuk dapat memiliki kemampuan yang sama dengan penutur asli.

Belajar dari penelitian ini meneliti tentang strategi komunikasi yang diterapakan dua orang guru EFL dan siswanya tingkat pemula [6]. Faktor potensial dapat mempengaruhi strategi komunikasi yang mereka terapkan di dalam kelas. Hasil penelitian ini menunjukkan strategi komunikasi yang dominan diterapkan dalam kedua kelompok merupakan alih bahasa. Tempat duduk siswa dan kegiatan pembelajaran menjadi salah satu faktor yang mempengaruhi strategi komunikasi yang diterapkan. Paragraf sebagian dari tulisan/bacaan yang terdiri atas beberapa kalimat yang utuh dan padu serta memiliki gagasan pokok yang jelas. Paragraf memiliki satu kalimat utama dan beberapa kalimat penjelas yang saling berkaitan sehingga membentuk 
kesatuan gagasan. Paragraf yang baik setidaknya memenuhi persyaratan, yakni kesatuan (kohesi) dan kepaduan (koheren).

\section{METODE PENELITIAN}

Pendekatan dalam penelitian kajian materi ajar bahasa Indonesia dasar menggunakan pendekatan kualitatif. Jenis penelitian kajian buku teks pelajaran ini dengan deskripsi sehingga strategi penelitian ini adalah deskriptif kualitatif [7]. Proses analisis deskriptif digunakan untuk collecting data yang digunakan untuk mengembangkan materi ajar. Analisis data pada penelitian ini menggunakan standar yang disusun dengan triangulasi teori dari beberapa ahli yang akan diperkuat, yakni pengkajian kelayakan isi, kelayakan penyajian, kelayakan bahasa, dan keterbacaan dalam materi ajar BIPA untuk keterampilan dasar membaca [8]. Pendeskripsian meliputi mengidentifikasi karakteristik kebahasaan pada materi ajar bahasa Indonesia.

Data penelitian kajian materi ajar dasar keterampilan menulis diperoleh melalui hasil menganalisis isi buku/materi ajar bahasa Indonesia. Data untuk rumusan pertama dan kedua adalah hasil analisis dengan instrumen penelitian yang akan disusun. Hasil instrumen berupa penskoran dari masing-masing butir yang dinilai dan komentar atau masukan yang akan dibubuhkan untuk melengkapi, membenarkan, dan memperbaiki isi buku tersebut baik dari segi isi maupun penyajian [9]. Kelayakan bahasa digunakan analisis kesalahan berbahasa untuk menemukan kesalahan penggunaan bahasa baik ketidakbaikan atau ketidakbenaran. Keterbacaan menggunakan data hasil penilaian cloze test atau tes rumpang.

\section{HASIL DAN PEMBAHASAN}

Bahasa sebagai bentuk keterampilan praktis membutuhkan banyak media preferensi untuk menunjang pembelajaran bahasa yang ebih mudah dipahami dan bisa diterima oleh pembelajar bahasa. Penggunaan kesatuan paragraf artinya kalimat tersebut mengandung satu ide pokok yang sama dan memiliki pembahasan dalam satu topik yang tidak menyimpang. Kalimat dalam paragraf tidak terlepas dari topik yang utuh agar bisa dipahami melalui proses berbahasa. Penggunaan kepaduan paragraf artinya dalam sebuah pargraf hendaknya memiliki hubungan satu kalimat dengan kalimat yang lain yang mendukung kalimat utama. Karangan persuasi bersifat mengajak atau memengaruhi pembaca agar percaya tentang isi karangan dan melakukan sesuatu sesuai dengan keinginan penulisnya. Empat materi keterampilan berbahasa dan sastra perlu disajikan secara proporsional. Hal tersebut berdasar dari perolehan bahasa seseorang yang berkesinambungan, yakni diawali dengan menyimak, berbicara, membaca, dan menulis. Sastra merupakan keterampilan apresiatif dari seorang yang belajar bahasa [10].

Proporsi yang dimaksud dalam penelitian ini tidak berarti memiliki jumlah yang sama, tapi setidaknya tidak mencapai dua kali lipat kurangnya dari keterampilan lain. Dalam hal ini, penulisan karangan persuasi hendaknya menggunakan kalimat yang efektif atau dengan kata lain penulis memperhatikan kalimat-kalimat yang ditulisnya agar pembaca dapat memahami maksud yang ingin disampaikan dan tidak menimbulkan salah tafsir.

Kalimat efektif memiliki ciri-ciri "di antaranya: (1) keutuhan, kesatuan, kelogisan, atau kesepadanan makna dan struktur; (2) kesejajaran bentuk kata dan unsur kalimat secara gramatikal; (3) kefokusan pikiran sehingga mudah dipahami oleh pembaca; (4) kehematan penggunaan unsur kalimat; (5) kecermatan dan kesantunan; dan (6) kevariasian kata dan struktur sehingga menghasilkan kesegaran bahasa" (Widjono dalam Rohmadi, dkk, 2014: 52). Berikut ini adalah beberapa contoh kesalahan dalam buku teks materi ajar menulis dasar. 
Kalimat yang efektif menggunakan kata yang ringkas. Dalam hal ini, kalimat yang efektif tidak memerlukan kata, frasa, atau unsur lain yang memiliki makna yang sama. Contoh: (1) Memanglah sangat sulit sekali untuk menghindari kabut asap yang sangat tebal itu.; (2) Dengan demikian sarapan pagi sangatlah penting untuk menjaga kesehatan kita dan masa depan kita.; (3) Pengaruhnya terhadap pada penerima pelajaran ilmu tersebut.; (4) Oleh karena itu, kita perlu untuk melestarikan budaya daerah guna meningkatkan minat dari generasi muda untuk lebih mengintergrasikan budaya.; (5) negara Indonesia mempunyai banyak sekali lagu-lagu daerah yang tersebar di seluruh Provinsi di Inonesia.

Kesejajaran dalam sebuah kalimat atau paragraf membutuhkan kesejajaran yang setara dengan konjungsi yang satu dengan yang lain. Bahasa yang baik menunjukkan tidak ada keperingkatan kalimat yang susah dipahami. Contoh: Masing-masing peserta luang dalam rapat agar tidak berdesak-desakkan di ruang yang sempit itu. Kalimat di atas memiliki unsur pembentuk kalimat yang tidak logis dan tidak masuk akal karena luang merupakan kata sifat sehingga tidak dapat diserahkan atau diberikan. Beberapa penataan dan grafis tulisan menggunakan kata atau diksi yang dicetak tebal dalam sebuah kalimat yang pada akhirnya menyebabkan kalimat tidak efektif sehingga sulit dipahami. Oleh karena itu, agar menjadi kalimat yang efektif maka dapat diperbaiki sebagai berikut.

Kesatuan kalimat sangat memengaruhi informasi yang disampaikan kepada pembaca. Salah satu hal yang memengaruhi kesepadanan struktur adalah penggunaan konjungsi yang tepat dalam sebuah kalimat. Buku teks yang digunakan dalam pembelajaran BIPA yang ditulis dengan bahasa asing (teradaptasi) menggunakan bahasa yang kurang bisa dipahami karena tidak menbgandung kesatuan ide/gagasan. Gagasan yang ditulis dengan jelas dapat mempermudah dalam menemukan pokok pikiran penulis agar diterima dengan baik oleh pembaca.

Kesalahan berbahasa yang digunakan dalam wacana memiliki beberapa kesalahan ejaan pada kesalahan pemakaian huruf, penulisan kata, dan pemakaian tanda baca. Selanjutnya, kesalahan pemakaian huruf dibatasi pada pemakaian huruf kapital. Kesalahan penulisan kata dibatasi pada penulisan kata ulang, preposisi atau kata depan, dan penulisan partikel. Kesalahan pemakaian tanda baca dibatasi pada tanda titik (.) dan tanda koma (,).

Berdasarkan Pedoman Umum Ejaan Bahasa Indonesia, kata depan di dan ke ditulis terpisah dari kata yang mengikutinya. Kata kedalam pada data seharusnya ditulis terpisah karena menunjukkan kata tempat. Kesalahan pada data terletak pada kata depan yang digabung, seharusnya ditulis terpisah dari kata yang mengikutinya. Kata depan di pada datayang diikuti dengan kata ganti waktu sehingga penulisannya tidak digabung. Kesalahan pada data terletak pada kata di yang diikuti dengan kata kerja ditulis terpisah.

Berbagai pengembangan paragraf tentunya mengurangi kebosanan dalam pembacaan suatu buku teks pelajaran, selain itu juga menambah teknik menulis peserta didik. Secara tidak langsung, peserta didik akan terbantu dengan berbagai pola pengembangan yang digunakan dalam sebuah buku untuk melatih kemampuan pribadinya. Sesuai dengan dasar pengembangan paragraf, ada beberapa pola yang dapat dipakai untuk mengembangkan paragraf, yaitu klimaks dan anti klimas, sudut pandangan, perbandingan-pertentangan, analogi, contoh, proses, sebabakibat, umum-khusus, klasifikasi, dan definisi luas.

Penulisan partikel pada data di atas kurang tepat karena tidak sesuai dengan kaidah ejaan yang berlaku. Penulisan partikel -pun pada dataseharusnya ditulis terpisah dari kata yang mendahuluinya. Sedangkan partikel - lah pada data seharusnya ditulis serangkai dengan kata yang mendahuluinya. Kesalahan pada data terletak pada pemakaian tanda titik yang diikuti dengan kata konjungsi [11]. Tanda titik yang digunakan pada kalimat pertama data tersebut kurang tepat karena kalimat selanjutnya menggunakan kata konjungsi di awal kalimat, yakni kata karena, sehingga, maka, atau, dan, tetapi, untuk, dan supaya. Kata konjungsi tersebut 
termasuk dalam jenis konjungsi intrakalimat. Dalam hal ini, konjungsi intrakalimat berfungsi untuk menghubungkan unsur kalimat dengan unsur lainnya atau bagian kalimat dengan bagian kalimat lainnya sehingga tidak terletak di awal kalimat. Dengan demikian, kata konjungsi jika diletakkan di awal kalimat maka kalimat tersebut menjadi tidak efektif. Seharusnya tanda titik sebelum kata konjungsi pada data di atas dihilangkan.

Beberapa kali kesalahan pada akhiran -an yang turut disandingkan dengan kata /hasil/. Hal tersebut kurang tepat, karena akhiran -an memiliki makna hasil. Dalam satu kalimat jika keduanya dipakai secara bersama-sama akan mubazir dan berlebih makna. Awalan me(n)- jika bertemu dengan kata yang diawali dengan konsonan $\mathrm{K}, \mathrm{T}, \mathrm{S}$, dan $\mathrm{P}$ maka hukum dalam tulisan tersebut konsonan akan luluh. Me(n)- bisa berubah menjadi me(ng)-, me(ny)-, me(n) atau $\mathrm{me}(\mathrm{m})$-. Konsistensi aturan dalam penggunaan bahasa Indonesia penting untuk menumbuhkan sifat berbiasa menggunakan bahasa yang benar. Selain itu juga perlu diidentifiikasi di- atau kesebagai kata depan atau awalan [12] [13].

Pemilihan ketiga teks tersebut karena jumlah kata yang tidak terlalu banyak yakni 300500 kata. Selain itu, ketiga bacaan tersebut memiliki tema yang menarik dan sesuai dengan perkembangan peserta didik. Ketiga bacaan tersebut diharapkan mampu mewakili seluruh bacaan yang disuguhkan dalam buku teks pelajaran tersebut.

Kata yang dilesapkan pada ketiga bacaan tersebut merupakan kata ke-7 karena sebelumnya telah dilakukan pengambilan sampel data dan menunjukkan tidak signifikannya beda pemilihan kata ke-7 maupun kata ke-10. Setelah kata ke-7 dalam teks tersebut dilesapkan, maka dibuat alternatif jawaban. Jawaban yang bersinonim atau sepadan dapat digantikan.

Tabel 1. Temuan kata dalam teks

\begin{tabular}{|c|c|c|c|c|c|}
\hline \multirow[t]{2}{*}{ Judul Teks } & \multirow{2}{*}{$\sum_{\text {Pembelajar }}$} & \multicolumn{4}{|c|}{ Persentase Keterbacaan } \\
\hline & & Tertinggi & Terendah & & Kriteria \\
\hline 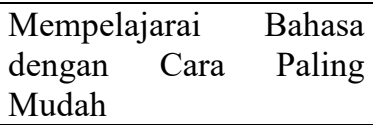 & 52 & 80 & 39 & 4 & Tinggi \\
\hline $\begin{array}{l}\text { Dampak Internet secara } \\
\text { Global }\end{array}$ & 54 & 77 & 23 & 0 & Tinggi \\
\hline $\begin{array}{l}\text { Bolehkah Membawa } \\
\text { Telepon Genggam saat } \\
\text { sedang Beribadah }\end{array}$ & 67 & 93 & 33 & 6 & Tinggi \\
\hline
\end{tabular}

Dari data di atas, ditemukan bahwa ketiga teks tersebut memiliki tingkat keterbacaan yang tinggi. Data paling menonjol pada keterbacaan Dampak Internet secara global yang nyaris pada kriteria sedang.

\section{SIMPULAN}

Di Indonesia masyarakat memiliki bahasa pertama yang beragam atau berbeda-beda, tetapi memiliki bahasa kedua yang sama, yaitu bahasa Indonesia yang digunakan sebgai bahasa nasional. Bahasa Indonesia digunakan secara alamiah dan buatan tergantung proses seseorang memperoleh bahasa Indonesia. Bahasa yang dipakai mahasiswa saat pembelajaran di kelas adalah bahasa kedua yang bukan bahasa asli pemelajar BIPA, mahasiswa perlu menyesuaikan agar dapat berbicara didepan kelas. Kemampuan bahasa non penutur asli membutuhkan tahapan untuk dapat memiliki kemampuan yang sama dengan penutur asli Kalimat yang efektif menggunakan kata yang ringkas. Dalam hal ini, kalimat yang efektif tidak memerlukan kata, frasa, atau unsur lain yang memiliki makna yang sama. Kesatuan kalimat sangat memengaruhi 
informasi yang disampaikan kepada pembaca. Salah satu hal yang memengaruhi kesepadanan struktur adalah penggunaan konjungsi yang tepat dalam sebuah kalimat. kata konjungsi jika diletakkan di awal kalimat maka kalimat tersebut menjadi tidak efektif. Seharusnya tanda titik sebelum kata konjungsi pada data di atas dihilangkan.

\section{REFERENCES}

[1] M. Sudaryanto, D. Mardapi, and S. Hadi, "How foreign speakers implement their strategies to listen indonesian language?," J. Adv. Res. Dyn. Control Syst., 2019.

[2] K. Saddhono, "Kajian Sosiolinguistik Pemakaian Bahasa Asing dalam Pembelajaran Bahasa Indonesia untuk Penutur Asing (BIPA) di Universitas Sebelas Maret," Kaji. Linguist. dan Sastra, 2012.

[3] M. Sudaryanto et al., "Indonesian as a Foreign Language: Standard Setting and Materials Development Issues," in 1st Workshop on Environmental Science, Society, and Technology, WESTECH, 2019, pp. 178-184.

[4] D. Agustin, "Penurunan Rasa Cinta Budaya Dan Nasionalisme Generasi Muda Akibat Globalisasi," J. Sos. Hum., 2011.

[5] M. Alqahtani, "The importance of vocabulary in language learning and how to be taught," Int. J. Teach. Educ., 2015.

[6] M. M. Zyoud, "Theoretical Perspective on How To Develop Speaking Skill," An Int. Multidiscip. J., 2016.

[7] A. M. M. Alwi, Soenjono Dardjowidjojo, Hans Lapoliwa, "Tata Bahasa Baku Bahasa Indonesia," Dep. Pendidik. dan Kebud. Republik Indones., 1998.

[8] A. Muhson, “Teknik Analisis Kuantitatif," Makal. Tek. Anal. II, 2006.

[9] M. Picard and L. Velautham, "Developing Independent Listening Skills for English as an Additional Language Students," Int. J. Teach. Learn. High. Educ., 2016.

[10] C. Suryanovika, I. M. Negara, S. Tinggi, B. Asing, and W. Hall, "Speech Act of The Bronte Sisters' Characters," Humanika, vol. 25, no. 2, pp. 75-87, 2018.

[11] T. Wiratno and R. Santosa, "Bahasa, Fungsi Bahasa, dan Konteks Sosial," Modul Pengantar Linguist. Umum, 2014.

[12] M. Rohmadi, “Analisis Wacana Pragmatik (Kajian Teori dan Analisanya),” in Analisis Wacana Pragmatik (Kajian Teori dan Analisanya), 2004.

[13] K. Saddhono, "Integrating culture in Indonesian language learning for foreign speakers at Indonesian universities," J. Lang. Lit., vol. 6, no. 2, 2015. 